\title{
Therapeutic detoxification of quercetin against carbon tetrachloride-induced acute liver injury in mice and its mechanism"
}

\author{
Jia-qi ZHANG ${ }^{1,2}$, Liang $\mathrm{SHI}^{1,2}$, Xi-ning $\mathrm{XU}^{2}$, Si-chong $\mathrm{HUANG}^{2}$, Bin LU ${ }^{1}$, Li-li JI ${ }^{\dagger+1}$, Zheng-tao WANG ${ }^{1}$ \\ $\left({ }^{l}\right.$ MOE Key Laboratory for Standardization of Chinese Medicines and Shanghai Key Laboratory of Complex Prescription, \\ Institute of Chinese Materia Medica, Shanghai University of Traditional Chinese Medicine, Shanghai 201203, China) \\ ( 2 School of Pharmacy, Shanghai University of Traditional Chinese Medicine, Shanghai 201203, China) \\ †E-mail: lichenyue1307@126.com \\ Received Apr. 14, 2014; Revision accepted July 20, 2014; Crosschecked Nov. 14, 2014
}

\begin{abstract}
This study observes the therapeutic detoxification of quercetin, a well-known flavonoid, against carbon tetrachloride $\left(\mathrm{CCl}_{4}\right)$ induced acute liver injury in vivo and explores its mechanism. Quercetin decreased $\mathrm{CCl}_{4}$-increased serum activities of alanine and aspartate aminotransferases (ALT/AST) when orally taken $30 \mathrm{~min}$ after $\mathrm{CCl}_{4}$ intoxication. The results of a histological evaluation further evidenced the ability of quercetin to protect against $\mathrm{CCl}_{4}$-induced liver injury. Quercetin decreased the $\mathrm{CCl}_{4}$-increased malondialdehyde (MDA) and reduced the glutathione (GSH) amounts in the liver. It also reduced the enhanced immunohistochemical staining of the 4-hydroxynonenal (4-HNE) in the liver induced by $\mathrm{CCl}_{4}$. Peroxiredoxin (Prx) 1, 2, 3, 5, 6, thioredoxin reductase 1 and 2 (TrxR1/2), thioredoxin 1 and 2 (Trx1/2), nuclear factor erythroid 2-related factor 2 (Nrf2), and heme oxygenase-1 (HO-1) all play critical roles in maintaining cellular redox homeostasis. Real-time polymerase chain reaction (PCR) results demonstrated that quercetin reversed the decreased mRNA expression of all those genes induced by $\mathrm{CCl}_{4}$. In conclusion, our results demonstrate that quercetin ameliorates $\mathrm{CCl}_{4}$-induced acute liver injury in vivo via alleviating oxidative stress injuries when orally taken after $\mathrm{CCl}_{4}$ intoxication. This protection may be caused by the elevation of the antioxidant capacity induced by quercetin.
\end{abstract}

Key words: Hepatotoxicity, Oxidative stress, Peroxiredoxin (Prx), Nuclear factor erythroid 2-related factor 2 (Nrf2), TrxR, Trx, HO-1

doi: $10.1631 /$ jzus.B1400104

Document code: A

CLC number: R96

\section{Introduction}

Flavonoids are widely distributed through red wine, fruits, vegetables, herbal tea and medicines. As flavonoids have various pharmacological activities, such as antioxidant, anti-inflammation, and anti-

\footnotetext{
* Corresponding author

* Project supported by the "Shu Guang" Project from Shanghai Municipal Education Commission and Shanghai Education Development Foundation (No. 13SG43), the National Natural Science Foundation of China (No. 81322053), and the Program for New Century Excellent Talents in University (No. NCET-11-1054), China

(D) ORCID: Li-li JI, http://orcid.org/0000-0001-6159-2626

(c) Zhejiang University and Springer-Verlag Berlin Heidelberg 2014
}

tumor, the nutritional value of flavonoids is wellknown to people (Hollman and Katan, 1999; Park and Pezzuto, 2012). Some epidemiological surveys report that a negative correlation can be observed between dietary intake of flavonoids and cardiovascular disease or cancer (Muldoon and Kritchevsky, 1996; Yang et al., 2001). However, nutraceuticals, including flavonoids, may also have toxic effects depending on the dose and the redox status of the cell, which is also called as hormesis (Brambilla et al., 2008; Calabrese et al., 2010). Quercetin is a well-known flavonoid, and it is widely distributed in various Chinese medicinal herbs, such as Flos sophorae Immaturus 
(Kelly, 2011; Wu et al., 2012). Various reports show that quercetin has neuro-protection, anti-tumor, antiinflammation, anti-oxidant, and anti-diabetic effects (Chirumbolo, 2010; Kelly, 2011; Dajas, 2012). Furthermore, some reports demonstrate that quercetin can ameliorate various toxin-induced liver injuries, such as ethanol and acetaminophen (Vicente-Sánchez et al., 2008; Liu et al., 2010; Yousef et al., 2010; de David et al., 2011; Domitrović et al., 2012). However, the concrete-engaged signals in regulating the protection of quercetin against liver injuries are not very clear.

Carbon tetrachloride $\left(\mathrm{CCl}_{4}\right)$, a classic hepatotoxin, has been widely used in the industry. $\mathrm{CCl}_{4}$ can enter the body of humans and animals primarily through the respiratory and digestive tracts. Weber $e t$ al. (2003) reported that $\mathrm{CCl}_{4}$ could lead to a lipid peroxidation of unsaturated fatty membrane and organelle membrane after its metabolic activation by hepatic microsomal cytochrome $\mathrm{P} 450$, and thus lead to serious hepatocytes damage. $\mathrm{CCl}_{4}$-induced liver injury is one of the most widely used experimental models for exogenous toxins-induced hepatotoxicity (Ratziu and Zelber-Sagi, 2009; Chen et al., 2012).

It have already demonstrated that pretreatment of mice or rats with quercetin for five consecutive days can prevent $\mathrm{CCl}_{4}$-induced acute liver injury (Janbaz et al., 2004; Domitrović et al., 2012; Cui et al., 2014). However, whether quercetin can also alleviate $\mathrm{CCl}_{4}$-induced acute liver injury, when it is given after intraperitoneal (i.p.) injection of $\mathrm{CCl}_{4}$, is unknown.

Peroxiredoxins (Prxs) and thioredoxins (Trxs) are important liver antioxidant proteins and play important roles in maintaining liver redox homeostasis (Watson et al., 2004; Rhee et al., 2005). The present study is designed to observe the therapeutic detoxification of quercetin against $\mathrm{CCl}_{4}$-induced liver injury when it is orally given after $\mathrm{CCl}_{4}$ intoxication, and to further investigate the underlying mechanisms via focusing on Prxs, Trxs, and other antioxidant signals.

\section{Materials and methods}

\subsection{Drugs and reagents}

Quercetin was purchased from Sigma (USA). Kits for analysis of alanine and aspartate aminotransferases (ALT/AST) and malondialdehyde
(MDA) were purchased from Nanjing Jiancheng Bioengineering Institute (Nanjing, China). Anti-4hydroxynonenal (4-HNE) antibody was purchased from Abcam (Cambridge, UK). The DAKO EnVision $^{\mathrm{TM}}$ detection system was purchased from DAKO Corporation (USA). The Trizol reagent was purchased from Life Technology (USA). PrimeScript RT master mix and SYBR Premix Ex Taq ${ }^{\mathrm{TM}}$ were all purchased from TaKaRa (Japan). Other reagents, unless noted, were purchased from Sigma (USA).

\subsection{Experimental animals}

Specific pathogen free male ICR mice (18-22 g) were purchased from the Shanghai Laboratory Animal Center of Chinese Academy of Science (Shanghai, China). Animals were fed with a standard laboratory diet and given free access to tap water. The animal room was maintained at $(22 \pm 1){ }^{\circ} \mathrm{C}$ and $(65 \pm$ $5) \%$ humidity, with a $12 \mathrm{~h}: 12 \mathrm{~h}$ light-dark cycle. The animals received humane care in compliance with the institutional animal care guidelines approved by the Experimental Animal Ethical Committee of Shanghai University of Traditional Chinese Medicine, China.

\subsection{Treatment of animals}

Quercetin was dissolved in a sodium hydroxide solution and kept in a dark storage area. The solution was adjusted to $\mathrm{pH}$ 9.0. $\mathrm{CCl}_{4}$ was dissolved in olive oil to a $25 \%$ concentration.

Mice were randomly divided into four groups with eight mice each. The vehicle group (control) was first injected with olive oil i.p., and 30 min later was orally given a $\mathrm{pH} 9.0$ vehicle solution. The $\mathrm{CCl}_{4}$ treated group was injected with $\mathrm{CCl}_{4}(15 \mathrm{ml} / \mathrm{kg}$; i.p.), and 30 min later was orally given a $\mathrm{pH} 9.0$ vehicle solution. The quercetin-treated groups were first injected with $\mathrm{CCl}_{4}$ solution i.p., and 30 min later were orally administered with quercetin 20 or $80 \mathrm{mg} / \mathrm{kg}$, respectively. Mice were sacrificed $24 \mathrm{~h}$ after $\mathrm{CCl}_{4}$ injection, and plasma and livers were collected.

\subsection{Analysis of ALT/AST activities}

Fresh blood was obtained from mice in the four groups and put at room temperature for $60 \mathrm{~min}$ to clot. Serum was isolated following the centrifugation at $840 \mathrm{~g}$ for $15 \mathrm{~min}$. Serum ALT and AST activities were determined by kits according to the manufacturer's instructions. 


\subsection{Histological examination}

Live slices were fixed in $10 \%$ phosphatebuffered saline (PBS)-formalin and embedded in paraffin. Liver samples were subsequently sectioned $(5 \mu \mathrm{m})$, stained with hematoxylin and eosin (H\&E), and examined under a microscope (Olympus, Japan) to evaluate liver injuries.

\subsection{Determination of tissue lipid peroxidation (LPO)}

Liver tissues were homogenized in cold PBS. LPO was determined according to the method described by Högberg et al. (1974). MDA was formed as the product of LPO and served as an index for LPO. MDA reacts with 2-thiobarbituric acid to generate a pink-colored product, which has an absorbance at $532 \mathrm{~nm}$. The MDA level was expressed as $\mu \mathrm{mol} / \mathrm{mg}$ protein based on liver protein concentration.

\subsection{Determination of liver glutathione (GSH)}

The amounts of liver GSH and oxidative GSH (GSSG) were measured as described in our previous report (Liang et al., 2011).

\section{8 Immunohistochemical staining of 4-HNE}

Paraffin-embedded liver sections $(5 \mu \mathrm{m})$ were first deparaffinized in xylene, and then rehydrated in a gradient of ethanol to distilled water. After quenching the endogenous peroxidase activity using $3 \%$ hydrogen peroxide, liver sections were further incubated with $5 \%$ bovine serum albumin to alleviate nonspecific binding, and then incubated with 4-HNE antibody at $4{ }^{\circ} \mathrm{C}$ overnight. The antigen-antibody reactions were detected using DAKO EnVision ${ }^{\mathrm{TM}}$ detection kits. All sections were counterstained with hematoxylin. Pictures were taken with a microscope (Nikon, Japan). Liver expression of 4-HNE was determined by image information object definition (IOD) values analyzed by Image-Pro Plus 6.0 (Media Cybernetics, USA).

\subsection{Real-time polymerase chain reaction (PCR)}

The total liver RNA was extracted by Trizol reagent as described by the manufacturer's protocol. Complementary DNA (cDNA) was synthesized according to the instruction of the PrimeScript RT master mix kits. Real-time PCR was performed with STEPONE Plus (Carlsbad, CA) by a SYBR green premix according to the manufacturer's guide. Relative expressions of target genes were standardized to $\beta$-actin, evaluated by the $2^{-\Delta \Delta C_{\mathrm{T}}}$ method and given as a ratio to control the experiments. The primer sequences used in this study are shown in Table 1.

Table 1 List of primers for real-time PCR

\begin{tabular}{|c|c|}
\hline Target & Primer sequence $\left(5^{\prime} \rightarrow 3^{\prime}\right)$ \\
\hline \multirow[t]{2}{*}{ Prx1 } & F: CACCCAAGAAACAAGGAGGA \\
\hline & R: AAAAAGGCCCCTGAAAGAGA \\
\hline \multirow[t]{2}{*}{$\operatorname{Prx} 2$} & F: TGATGAGGGCATTGCTTACAGG \\
\hline & R: GAGCGTCCCACAGGTAGGTCAT \\
\hline \multirow[t]{2}{*}{$\operatorname{Prx} 3$} & F: TTCCCACTTCAGTCATCTTGCC \\
\hline & R: ATGCCAGCACTTTCCAACAGC \\
\hline \multirow[t]{2}{*}{$\operatorname{Prx} 4$} & F: TTCCTGTTGCGGACCGAAT \\
\hline & R: TACACTTGTCCACCAGCGTAGAA \\
\hline \multirow[t]{2}{*}{$\operatorname{Prx} 5$} & F: GGAAGGCGACAGACTTATTATTGG \\
\hline & R: CCTTCACTATGCCGTTGTCTATCAC \\
\hline \multirow[t]{2}{*}{ Prx6 } & F: GCACCACAGAACTTGGCAGAG \\
\hline & R: CCAGGCAAGATGATCCTCAACA \\
\hline \multirow[t]{2}{*}{$\operatorname{Trx} 1$} & F: TCCCTCCCCGCAACAGCCAA \\
\hline & R: ACCGGAGAACTCCCCCACCTTT \\
\hline \multirow[t]{2}{*}{$\operatorname{Tr} 2$} & F: TCGCCAAGCAGCACGGGAAG \\
\hline & R: CGGTAGGCACAGCTGACACCTCA \\
\hline \multirow[t]{2}{*}{ TrxR1 } & F: TCGGCTCGCTGAACTGGGG \\
\hline & R: GCGATGA GGAACCGCTCTGCTG \\
\hline \multirow[t]{2}{*}{ TrxR2 } & F: GATCGGTGGGGGATCCGGTG \\
\hline & R: CCCACTTGGTGCCTCGGGGAG \\
\hline \multirow[t]{2}{*}{ HO-1 } & F: TCCCGAACATCGACAGCCCCA \\
\hline & R: AGGGGCAGTATCTTGCACCAGG \\
\hline \multirow[t]{2}{*}{ Nrf2 } & F: TCTCCTCGCTGGAAAAAGAA \\
\hline & R: AATGTGCTGGCTGTGCTTTA \\
\hline \multirow[t]{2}{*}{ Actin } & F: TTCGTTGCCGGTCCACACCC \\
\hline & R: GCTTTGCACATGCCGGAGCC \\
\hline
\end{tabular}

F: forward primer; R: reverse primer

\subsection{Statistical analysis}

All experimental data were expressed as mean \pm standard error of the mean (SEM). Significant differences were determined by one-way analysis of variance (ANOVA). $P<0.05$ was considered as a statistically significant difference. 


\section{Results}

\subsection{Quercetin ameliorates $\mathrm{CCl}_{4}$-induced acute liver injury}

Serum activities of ALT and AST were increased in the $\mathrm{CCl}_{4}$ group compared with the control group $(P<0.001$; Fig. 1). After treatment with quercetin $(80 \mathrm{mg} / \mathrm{kg}), \mathrm{CCl}_{4}$-increased ALT and AST activities were decreased $(P<0.05$ and $P<0.01$, respectively). Quercetin $(20 \mathrm{mg} / \mathrm{kg})$ had no effect on $\mathrm{CCl}_{4-}$ increased serum ALT or AST activity. In contrast to the control group, the mice in the $\mathrm{CCl}_{4}$ group showed serious liver damage, indicated by obvious hepatocyte necrosis and shrinkage nuclei (Fig. 2b). After treatment with quercetin $(20$ and $80 \mathrm{mg} / \mathrm{kg}$ ), these abnormal changes were all alleviated (Figs. $2 \mathrm{c}$ and 2d).

\subsection{Quercetin alleviates $\mathrm{CCl}_{4}$-induced liver oxi- dative injury}

As the product of LPO, the MDA amount can reflect the liver LPO level (Högberg et al., 1974).
Fig. 3a shows that the liver MDA amount increased significantly $(P<0.05)$ in the $\mathrm{CCl}_{4}$-treated mice when compared with the control group. Quercetin $(80 \mathrm{mg} / \mathrm{kg})$ reduced the increased MDA amount induced by $\mathrm{CCl}_{4}(P<0.05)$. Quercetin $(20 \mathrm{mg} / \mathrm{kg})$ also reduced the increased MDA amount, but it showed no significant difference when compared with the $\mathrm{CCl}_{4}$ group $(P>0.05)$.

GSH is a cellular important antioxidant and it can protect cells against reactive oxygen species (ROS)-induced liver injury (Yuan and Kaplowitz, 2009). As shown in Fig. 3b, the liver GSH level in $\mathrm{CCl}_{4}$-treated mice was enhanced compared with the control group $(P<0.05)$. Quercetin $(20$ or $80 \mathrm{mg} / \mathrm{kg}$ ) decreased the $\mathrm{CCl}_{4}$-increased liver GSH level $(P<0.05)$.

In addition, our results showed that the number of 4-HNE-stained hepatocytes increased in the $\mathrm{CCl}_{4}$ treated mice (Fig. 4b). Quercetin (20 or $80 \mathrm{mg} / \mathrm{kg}$ ) reduced the $\mathrm{CCl}_{4}$-increased 4-HNE-stained cells (Figs. 4c and 4d). The statistical result in Fig. 4e
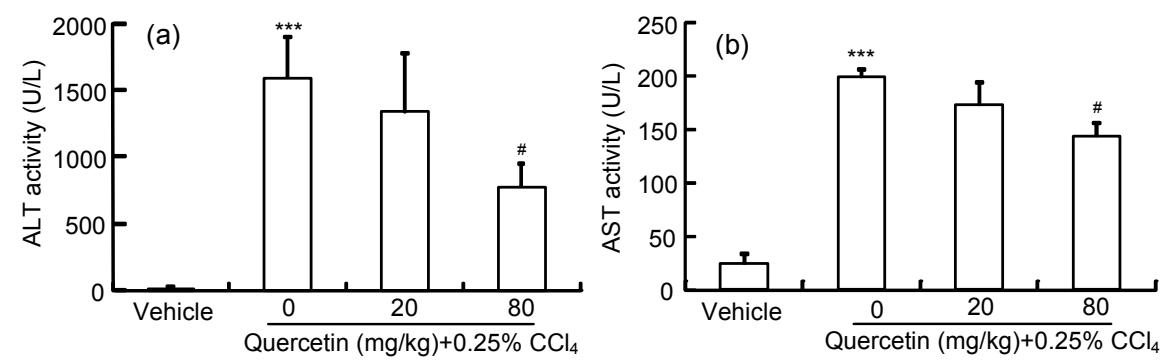

Fig. 1 Serum ALT (a) and AST (b) activities in mice Data are shown as mean \pm SEM $(n=8) .{ }^{* * *} P<0.001$ vs. control; \# $P<0.05$ vs. $\mathrm{CCl}_{4}$-treated group
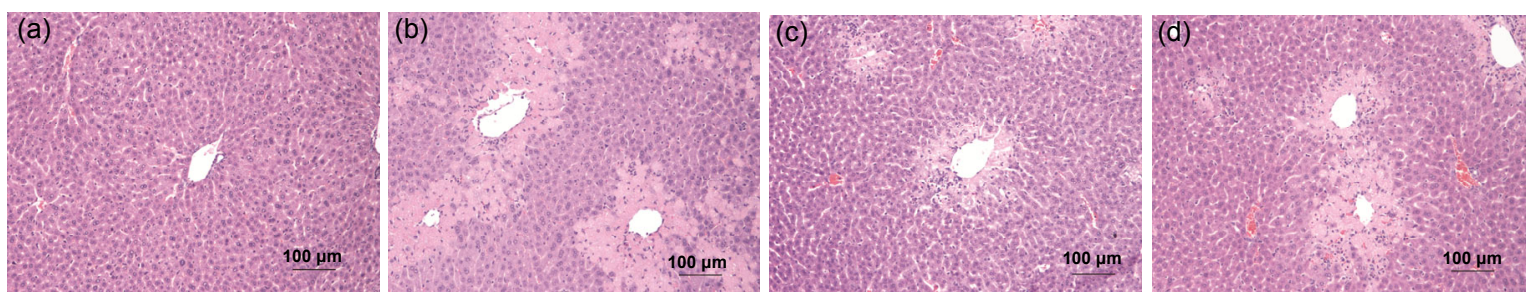

Fig. 2 Histological evaluation of liver by $\mathrm{H} \& \mathrm{E}$ staining

(a) Vehicle group; (b) $\mathrm{CCl}_{4}$ group; (c) $\mathrm{CCl}_{4}+20 \mathrm{mg} / \mathrm{kg}$ quercetin group; (d) $\mathrm{CCl}_{4}+80 \mathrm{mg} / \mathrm{kg}$ quercetin group
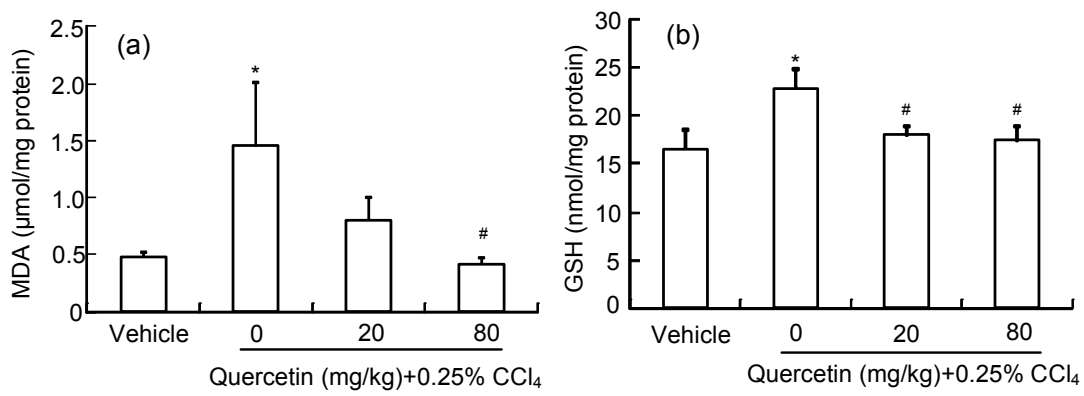

Fig. 3 Liver MDA (a) and GSH (b) amounts in mice Data are shown as mean \pm SEM $(n=8) .{ }^{*} P<0.05$ vs. control; ${ }^{\#} P<0.05$ vs. $\mathrm{CCl}_{4}$-treated group 

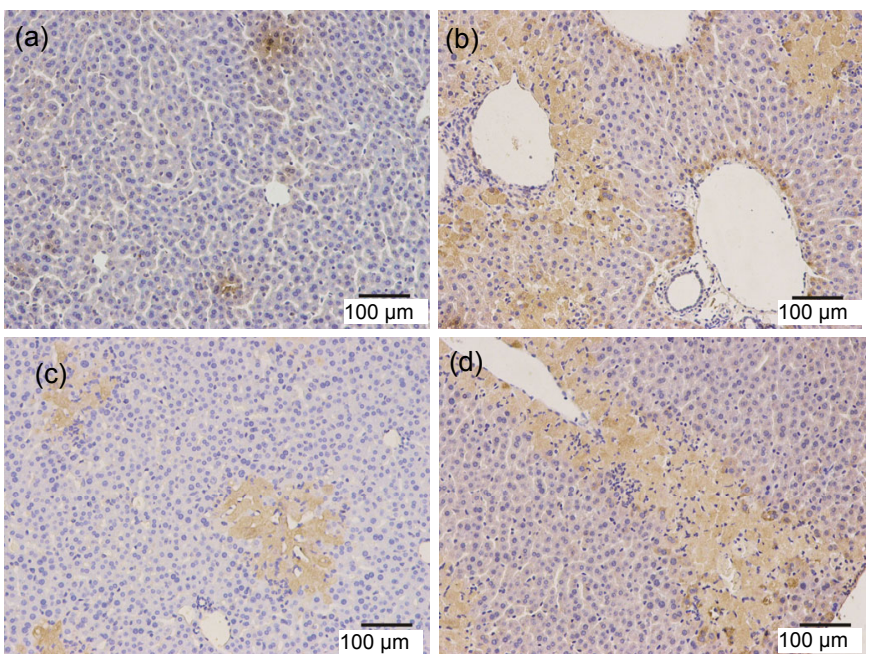

(e)

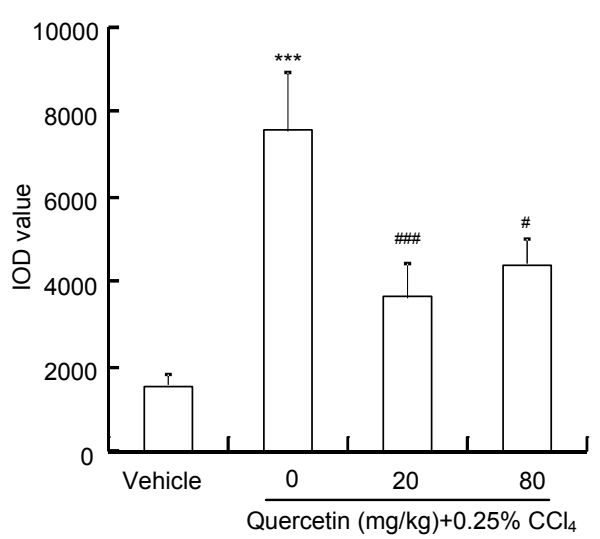

Fig. 4 Immunohistochemical staining of 4-HNE in mice livers and IOD values of the density of 4-HNE Typical images selected from each group: (a) vehicle control; (b) $\mathrm{CCl}_{4}$; (c) $\mathrm{CCl}_{4}+20 \mathrm{mg} / \mathrm{kg}$ quercetin; (d) $\mathrm{CCl}_{4}+80 \mathrm{mg} / \mathrm{kg}$ quercetin. (e) IOD values of the density of 4-HNE staining analyzed in every section of at least three random fields. Data are expressed as mean $\pm \operatorname{SEM}(n=4) .{ }^{* * *} P<0.001$ vs. control; ${ }^{\#} P<0.05,{ }^{\# \#} P<0.001$ vs. $\mathrm{CCl}_{4}$-treated group

showed that $\mathrm{CCl}_{4}$ enhanced the density of the immunohistochemical staining of 4-HNE $(P<0.001)$, while quercetin $(20$ and $80 \mathrm{mg} / \mathrm{kg}$ ) decreased this increase induced by $\mathrm{CCl}_{4}(P<0.001$ and $P<0.05$, respectively).

\subsection{Effects of quercetin on Prx 1-6 mRNA expression}

As shown in Fig. 5, the liver mRNA expressions of Prx 1-3, 5, 6 in $\mathrm{CCl}_{4}$-treated mice all decreased remarkably compared with the control group $(P<0.001)$. After treatment with quercetin $(20 \mathrm{mg} / \mathrm{kg})$, the mRNA expressions of Prx 1, Prx 2, Prx 3, Prx 5, and Prx 6 all increased when compared with the $\mathrm{CCl}_{4}$-treated mice $(P<0.01, P<0.001, P<0.05, P<0.01$, and $P<0.01$, respectively). The mRNA expressions of $\operatorname{Prx} 1$, Prx 2, and Prx 6 in $80 \mathrm{mg} / \mathrm{kg}$ quercetin-treated mice also increased when compared with the $\mathrm{CCl}_{4}$-treated mice $(P<0.05, P<0.05$, and $P<0.001$, respectively).

\subsection{Effects of quercetin on $\operatorname{Trx} 1 / 2$ and TrxR1/2 mRNA expression}

The liver mRNA expressions of other antioxidant enzymes, such as Trx1/2 and TrxR1/2, all decreased in the $\mathrm{CCl}_{4}$-treated mice when compared with the control group $(P<0.01$ and $P<0.001$, respectively) (Fig. 6). After treatment with $20 \mathrm{mg} / \mathrm{kg}$ quercetin, the mRNA expressions of Trx $1 / 2$ and TrxR $1 / 2$ were all
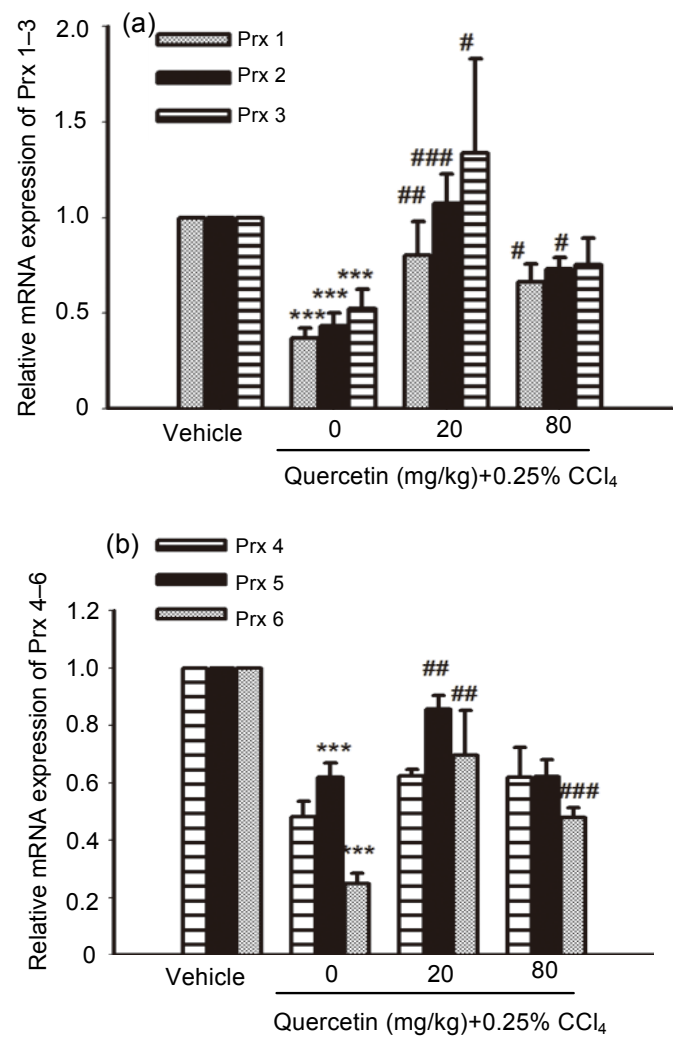

Fig. 5 mRNA expressions of Prx 1-3 (a) and Prx 4-6 (b) in mice livers

Data are shown as mean \pm SEM $(n=5-6) .{ }^{* * *} P<0.001$ vs. control; ${ }^{\#} P<0.05,{ }^{\#} P<0.01,{ }^{\# \#} P<0.001$ vs. $\mathrm{CCl}_{4}$-treated mice 

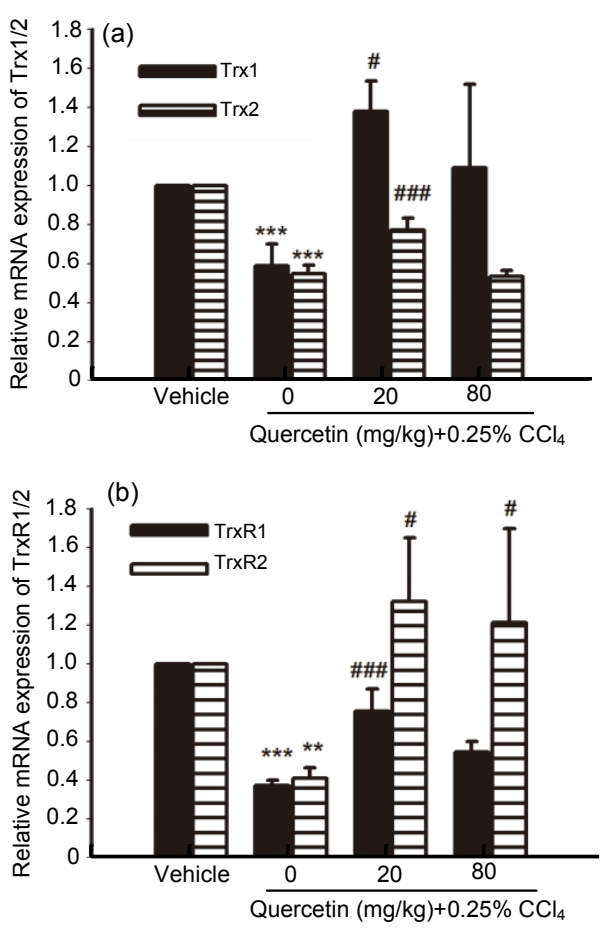

Fig. 6 mRNA expressions of $\operatorname{Trx} 1 / 2$ (a) and $\operatorname{TrxR1/2}(\mathrm{b})$ in mice livers

Data are shown as mean \pm SEM $(n=5-6) .^{* *} P<0.01$, ${ }^{\text {*** }} P<0.001$ vs. control; ${ }^{\#} P<0.05,{ }^{\# \#} P<0.001$ vs. $\mathrm{CCl}_{4^{-}}$ treated mice

elevated when compared with the $\mathrm{CCl}_{4}$-treated mice $(P<0.05$ and $P<0.001$, respectively). After treatment with $80 \mathrm{mg} / \mathrm{kg}$ quercetin, the mRNA expression of TrxR2 increased when compared with the $\mathrm{CCl}_{4}$-treated mice $(P<0.05)$.

3.5 Effects of quercetin on the mRNA expression of HO-1 and nuclear factor erythroid 2-related factor 2 (Nrf2)

The liver mRNA expressions of HO-1 and Nrf2 in $\mathrm{CCl}_{4}$-treated mice decreased when compared with the control group $(P<0.001$ and $P<0.05$, respectively) (Fig. 7). After treatment with $20 \mathrm{mg} / \mathrm{kg}$ quercetin, the liver mRNA expressions of HO-1 and $\mathrm{Nrf} 2$ increased when compared with the $\mathrm{CCl}_{4}$-treated mice $(P<0.01$ and $P<0.05$, respectively).

\section{Discussion}

$\mathrm{CCl}_{4}$-induced acute liver injury in mice is widely used as an experimental animal model for screening

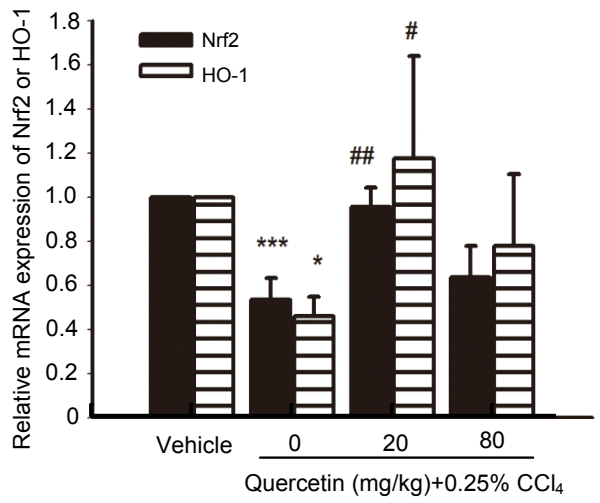

Fig. 7 Liver mRNA expressions of HO-1 and Nrf2 Data are shown as mean \pm SEM $(n=5-6) .{ }^{*} P<0.05$, ${ }^{* * *} P<0.001$ vs. control; ${ }^{\#} P<0.05,{ }^{\#} P<0.01$ vs. $\mathrm{CCl}_{4}$-treated mice

hepato-protective drugs (Morio et al., 2001; Yuan et al., 2008). Some previous studies have already demonstrated that quercetin can prevent $\mathrm{CCl}_{4}$ induced acute liver injury when given several days before $\mathrm{CCl}_{4}$ intoxication (Janbaz et al., 2004; Domitrović et al., 2012; Cui et al., 2014). From the results of ALT/AST analysis and histological observations, our study demonstrates that quercetin can ameliorate $\mathrm{CCl}_{4}$-induced acute liver injury when it is given $30 \mathrm{~min}$ after $\mathrm{CCl}_{4}$ intoxication. Our study shows the potential therapeutic effects of quercetin against $\mathrm{CCl}_{4}$-induced acute liver injury, and its scientific significance is far more important than indicated in previous reports.

Generally, oxidative stress liver injuries are the main reason for $\mathrm{CCl}_{4}$-induced hepatotoxicity. 4-HNE and MDA are both the end-products of LPO (Högberg et al., 1974; Vatsyayan et al., 2011). Our results of liver MDA level and immunohistochemical staining of 4-HNE show that quercetin can decrease $\mathrm{CCl}_{4-}$ induced LPO, which indicates that quercetin can ameliorate $\mathrm{CCl}_{4}$-induced liver oxidative injuries. GSH is the key antioxidant in liver, and its homeostasis is associated with various toxin-induced liver injuries (Kretzschmar and Klinger, 1990; Han et al., 2006). Further results show that $\mathrm{CCl}_{4}$ increased the cellular GSH level, which may contribute to the elevation of the body's defensive capacity to protect $\mathrm{CCl}_{4}$-induced oxidative stress injuries. After treatment with quercetin, the increased liver GSH level was reduced, which suggests that oxidative stress injuries were ameliorated. There are already existing 
reports that state that quercetin has a free radical scavenging activity (Pascoal et al., 2011; di Meo et al., 2013), so we can speculate that quercetin itself may have the capacity to scavenge free radicals, and thus substitute for the function of GSH, which leads to a decrease of GSH levels in quercetin-treated mice.

The Prx family contains Prx 1-6, which are all antioxidant enzymes and have the capacity of scavenging free radicals in cells (Rhee et al., 2005). Previous reports have demonstrated the changed expression of the Prx family in exogenous toxin-induced liver injuries such as alcoholic liver injury and pyrazole-induced liver injury (Cohen et al., 2011; Bae et al., 2012). In addition, Hong et al. (2011) reported that an alkaline water named ENA actimineral resource A (ENA-A) could prevent $\mathrm{CCl}_{4}$-induced liver injury, and Prx1 is an increased component in the ENA-A group. Our results showed that the expressions of Prx 1-6 mRNAs in the $\mathrm{CCl}_{4}$-treated group all decreased when compared with the vehicle group. Except Prx 4, the mRNA expressions of all the other members of the Prx family increased in quercetintreated mice. Our study suggests that quercetin can ameliorate liver oxidative injuries via elevating the expressions of Prx 1, 2, 3, 5, 6 .

Trxs, including Trx1 and Trx2, are cellular important antioxidant proteins (Watson et al., 2004). Trx 1/2 and Trx reductase 1/2 (TrxR1/2) constitute the Trx system, which plays a partially overlapping and highly complementary role to the GSH antioxidant system, and contributes to the maintenance of the cellular reducing environment (Williams et al., 2000). Our results show that the mRNA expressions of Trx $1 / 2$ and TrxR1/2 decreased in the $\mathrm{CCl}_{4}$-treated mice, but this decrease was reversed in the quercetintreated mice. These results suggest that quercetin can ameliorate liver oxidative injuries via elevating the expression of the Trx system.

HO-1 is the inducible isoform of heme oxygenase, and it is reported to protect acute liver injuries (Sass et al., 2012). Our results showed that the mRNA expression of $\mathrm{HO}-1$ decreased in the $\mathrm{CCl}_{4}$-treated mice, but this decrease was reversed in the quercetintreated mice. This result suggests that the increased HO-1 expression may contribute to the alleviation of quercetion against $\mathrm{CCl}_{4}$-induced liver injury. It is well-known that $\mathrm{HO}-1 /$ biliverdin reductase axis catalyzes the degradation of heme, and it can also reduce biliverdin to bilirubin, which is a free radical scavenger and exerts cytoprotective effects (Barone et al., 2009; Mancuso and Barone, 2009; Mancuso et al., 2012). Whether quercetin will affect the amounts of liver bilirubin needs further investigation.

$\mathrm{Nrf} 2$ is a critical transcription factor for regulating the expression of some antioxidant enzymes, such as HO-1, Prxs, and Trx1 (Young et al., 2010; Yang et al., 2011; Ke et al., 2013). Our results show that the mRNA expression of Nrf2 decreased in the $\mathrm{CCl}_{4}$-treated mice, but this decrease was reversed in the quercetin-treated mice. The above results suggest that $\mathrm{CCl}_{4}$ can regulate the expression of $\mathrm{Nrf} 2$ and quercetin can ameliorate the liver oxidative injuries via elevating the expression of Nrf2, which may contribute to the increased expression of its downstream antioxidant enzymes. Moreover, the increased expressions of these antioxidant enzymes by quercetin may not provide the appropriate regulation through Nrf2, which needs further investigation.

In conclusion, the present study demonstrates the therapeutic detoxification of quercetin against $\mathrm{CCl}_{4}$-induced acute liver injury in vivo. Our results show that quercetin can ameliorate $\mathrm{CCl}_{4}$-induced liver injury through inhibiting oxidative stress injury via elevating the expressions of the antioxidant transcription factor Nrf2 and some antioxidant enzymes, such as HO-1, Prx 1-3, Prx 5-6, Trx1/2, and TrxR1/2.

\section{Compliance with ethics guidelines}

Jia-qi ZHANG, Liang SHI, Xi-ning XU, Si-chong HUANG, Bin LU, Li-li JI, and Zheng-tao WANG declare that they have no conflict of interest.

All institutional and national guidelines for the care and use of laboratory animals were followed.

\section{References}

Bae, S.H., Sung, S.H., Lee, H.E., et al., 2012. Peroxiredoxin III and sulfiredoxin together protect mice from pyrazoleinduced oxidative liver injury. Antioxid. Redox Signal., 17(10):1351-1361. [doi:10.1089/ars.2011.4334]

Barone, E., Trombino, S., Cassano, R., et al., 2009. Characterization of the $S$-denitrosylating activity of bilirubin. $J$. Cell. Mol. Med., 13(8b):2365-2375. [doi:10.1111/j.15824934.2008.00680.x]

Brambilla, D., Mancuso, C., Scuderi, M.R., et al., 2008. The role of antioxidant supplement in immune system, neoplastic, and neurodegenerative disorders: a point of view for an assessment of the risk/benefit profile. Nutr. J., 7(1):29. [doi:10.1186/1475-2891-7-29] 
Calabrese, V., Cornelius, C., Trovato-Salinaro, A., et al., 2010. The hormetic role of dietary antioxidants in free radicalrelated diseases. Curr. Pharm. Des., 16(7):877-883. [doi:10.2174/138161210790883615]

Chen, P., Wang, Z., Zeng, L., et al., 2012. Protective effects of salecan against carbon tetrachloride-induced acute liver injury in mice. J. Appl. Toxicol., 32(10):796-803. [doi:10. 1002/jat.1694]

Chirumbolo, S., 2010. The role of quercetin, flavonols and flavones in modulating inflammatory cell function. Inflamm. Allergy Drug Targets, 9(4):263-285. [doi:10. 2174/187152810793358741]

Cohen, J.I., Chen, X., Nagy, L.E., 2011. Redox signaling and the innate immune system in alcoholic liver disease. $A n$ tioxid. Redox Signal., 15(2):523-534. [doi:10.1089/ars. 2010.3746]

Cui, Y.M., Han, Y., Yang, X.B., et al., 2014. Protective effects of quercetin and quercetin-5',8-disulfonate against carbon tetrachloride-caused oxidative liver injury in mice. Molecules, 19(1):291-305. [doi:10.3390/molecules 19010291]

Dajas, F., 2012. Life or death: neuroprotective and anticancer effects of quercetin. J. Ethnopharmacol., 143(2):383-396. [doi:10.1016/j.jep.2012.07.005]

de David, C., Rodrigues, G., Bona, S., et al., 2011. Role of quercetin in preventing thioacetamide-induced liver injury in rats. Toxicol. Pathol., 39(6):949-957. [doi:10. 1177/0192623311418680]

di Meo, F., Lemaur, V., Cornil, J., et al., 2013. Free radical scavenging by natural polyphenols: atom versus electron transfer. J. Phys. Chem. A, 117(10):2082-2092. [doi:10. 1021/jp3116319]

Domitrović, R., Jakovac, H., Marchesi, V.V., et al., 2012. Differential hepatoprotective mechanisms of rutin and quercetin in $\mathrm{CCl}_{4}$-intoxicated BALB/cN mice. Acta Pharmacol. Sin., 33(10):1260-1270. [doi:10.1038/aps.2012.62]

Han, D., Hanawa, N., Saberi, B., et al., 2006. Mechanisms of liver injury. III. Role of glutathione redox status in liver injury. Am. J. Physiol. Gastrointest. Liver Physiol., 291(1): G1-G7. [doi:10.1152/ajpgi.00001.2006]

Högberg, J., Larson, R.E., Kristoferson, A., et al., 1974. NADPH-dependent reductase solubilized from microsomes by peroxidation and its activity. Biochem. Biophys. Res. Commun., 56(3):836-842. [doi:10.1016/0006-291X (74)90681-0]

Hollman, P.H., Katan, M.B., 1999. Dietary flavonoids: intake, health effects and bioavailability. Food Chem. Toxicol., 37(9-10):937-942. [doi:10.1016/S0278-6915(99)00079-4]

Hong, I.H., Ji, H., Hwa, S.Y., et al., 2011. The protective effect of ENA actimineral resource $\mathrm{A}$ on $\mathrm{CCl}_{4}$-induced liver injury in rats. Mar. Biotechnol., 13(3):462-473. [doi:10. 1007/s10126-010-9317-8]

Janbaz, K.H., Saeed, S.A., Gilani, A.H., 2004. Studies on the protective effects of caffeic acid and quercetin on chemical-induced hepatotoxicity in rodents. Phytomedicine, 11(5):424-430. [doi:10.1016/j.phymed.2003.05.002]

Ke, B., Shen, X.D., Zhang, Y., et al., 2013. KEAP1-NRF2 complex in ischemia-induced hepatocellular damage of mouse liver transplants. J. Hepatol., 59(6):1200-1207. [doi:10.1016/j.jhep.2013.07.016]

Kelly, G.S., 2011. Quercetin. Altern. Med. Rev., 16(2): 172-194.

Kretzschmar, M., Klinger, W., 1990. The hepatic glutathione system-influences of xenobiotics. Exp. Pathol., 38(3): 145-164. [doi:10.1016/S0232-1513(11)80201-X]

Liang, Q.N., Sheng, Y.C., Jiang, P., et al., 2011. The difference of glutathione antioxidant system in newly weaned and young mice liver and its involvement in isoline-induced hepatotoxicity. Arch. Toxicol., 85(10):1267-1279. [doi:10. 1007/s00204-011-0664-7]

Liu, C.M., Zheng, Y.L., Lu, J., et al., 2010. Quercetin protects rat liver against lead-induced oxidative stress and apoptosis. Environ. Toxicol. Pharmacol., 29(2):158-166. [doi: 10.1016/j.etap.2009.12.006]

Mancuso, C., Barone, E., 2009. The heme oxygenase/ biliverdin reductase pathway in drug research and development. Curr. Drug Metab., 10(6):579-594. [doi:10. 2174/138920009789375405]

Mancuso, C., Barone, E., Guido, P., et al., 2012. Inhibition of lipid peroxidation and protein oxidation by endogenous and exogenous antioxidants in rat brain microsomes in vitro. Neurosci. Lett., 518(2):101-105. [doi:10.1016/j. neulet.2012.04.062]

Morio, L.A., Chiu, H., Sprowles, K.A., et al., 2001. Distinct roles of tumor necrosis factor- $\alpha$ and nitric oxide in acute liver injury induced by carbon tetrachloride in mice. Toxicol. Appl. Pharmacol., 172(1):44-51. [doi:10.1006/ taap.2000.9133]

Muldoon, M.F., Kritchevsky, S.B., 1996. Flavonoids and heart disease. $B M J$, 312(7029):458-459. [doi:10.1136/bmj. 312.7029.458]

Park, E.J., Pezzuto, J.M., 2012. Flavonoids in cancer prevention. Anti-Cancer Agents Med. Chem., 12(8):836-851. [doi:10.2174/187152012802650075]

Pascoal, A.C., Ehrenfried, C.A., Eberline, M.N., et al., 2011. Free radical scavenging activity, determination of phenolic compounds and HPLC-DAD/ESI-MS profile of Campomanesia adamantium leaves. Nat. Prod. Commun., 6(7):969-972.

Ratziu, V., Zelber-Sagi, S., 2009. Pharmacologic therapy of non-alcoholic steatohepatitis. Clin. Liver Dis., 13(4): 667-688. [doi:10.1016/j.cld.2009.07.001]

Rhee, S.G., Chae, H.Z., Kim, K., 2005. Peroxiredoxins: a historical overview and speculative preview of novel mechanisms and emerging concepts in cell signaling. Free Radic. Biol. Med., 38(12):1543-1552. [doi:10.1016/ j.freeradbiomed. 2005.02.026]

Sass, G., Barikbin, R., Tiegs, G., 2012. The multiple functions of heme oxygenase-1 in the liver. Z. Gastroenterol., 50(1):34-40. [doi:10.1055/s-0031-1282046.]

Vatsyayan, R., Chaudhary, P., Sharma, A., et al., 2011. Role of 4-hydroxynonenal in epidermal growth factor receptormediated signaling in retinal pigment epithelial cells. Exp. 
Eye Res., 92(2):147-154. [doi:10.1016/j.exer.2010.11.010]

Vicente-Sánchez, C., Egido, J., Sánchez-González, P.D., et al., 2008. Effect of flavonoid quercetin on cadmium-induced hepatotoxicity. Food Chem. Toxicol., 46(6):2279-2287. [doi:10.1016/j.fct.2008.03.009]

Watson, W.H., Yang, X., Choi, Y.E., et al., 2004. Thioredoxin and its role in toxicology. Toxicol. Sci., 78(1):3-14. [doi:10.1093/toxsci/kfh050]

Weber, L.W., Boll, M., Stampfl, A., 2003. Hepatotoxicity and mechanism of action of haloalkanes: carbon tetrachloride as a toxicological model. Crit. Rev. Toxicol., 33(2): 105-136. [doi:10.1080/713611034]

Williams, C.H.Jr., Arscott, L.D., Müller, S., et al., 2000. Thioredoxin reductase: two modes of catalysis have evolved. Eur. J. Biochem., 267(20):6110-6117. [doi:10.1046/j. 1432-1327.2000.01702.x]

Wu, H., Chen, M., Fan, Y., et al., 2012. Determination of rutin and quercetin in Chinese herbal medicine by ionic liquidbased pressurized liquid extraction-liquid chromatographychemiluminescence detection. Talanta, 88:222-229. [doi:10.1016/j.talanta.2011.10.036]

Yang, C.S., Landau, J.M., Huang, M.T., et al., 2001. Inhibition of carcinogenesis by dietary polyphenolic compounds. Ann. Rev. Nutr., 21(1):381-406. [doi:10.1146/annurev. nutr.21.1.381]
Yang, Y.C., Lii, C.K., Lin, A.H., et al., 2011. Induction of glutathione synthesis and heme oxygenase 1 by the flavonoids butein and phloretin is mediated through the ERK/Nrf2 pathway and protects against oxidative stress. Free Radic. Biol. Med., 51(11):2073-2081. [doi:10.1016/ j.freeradbiomed.2011.09.007]

Young, R., Hayes, J.D., Brown, K., et al., 2010. Peroxiredoxin gene expression signatures in liver reflect toxic insult. ASSAY Drug Dev. Technol., 8(4):512-517. [doi:10.1089/ adt.2009.0246]

Yousef, M.I., Omar, S.A., El-Guendi, M.I., et al., 2010. Potential protective effects of quercetin and curcumin on paracetamol-induced hitological changes, oxidative stress, impaired liver and kidney functions and haematotoxicity in rat. Food Chem. Toxicol., 48(11):3246-3261. [doi:10. 1016/j.fct.2010.08.034]

Yuan, L., Kaplowitz, N., 2009. Glutathione in liver diseases and hepatotoxicity. Mol. Aspects Med., 30(1-2):29-41. [doi:10.1016/j.mam.2008.08.003]

Yuan, L.P., Chen, F.H., Ling, L., et al., 2008. Protective effects of total flavonoids of Bidens bipinnata L. against carbon tetrachloride-induced liver fibrosis in rats. J. Pharm. Pharmacol., 60(10):1393-1402. [doi:10.1211/jpp/60.10. 0016]

\section{中文㩯要：}

\section{本文题目：梀皮素对四氯化碳引起的小鼠急性肝损伤治疗作用及其机理}

Therapeutic detoxification of quercetin against carbon tetrachloride-induced acute liver injury in mice and its mechanism

研究目的: 本研究旨在观察槲皮素对四氯化碳 $\left(\mathrm{CCl}_{4}\right)$ 诱导的肝损伤的治疗解毒作用及其机理。

创新要点: 首次发现檞皮素对 $\mathrm{CCl}_{4}$ 诱导的肝损伤有治疗作用, 并且首次发现 Prx 和 Trx 家族参与其中。

研究方法: 检测小鼠血清转氨酶含量, 并检测肝组织中丙二醛（MDA）、谷胱甘肽 (GSH) 和 4-羟基 壬烯醛（4-HNE）含量, 并用实时聚合酶链式反应（PCR）检测肝组织中 Prx 1-6、TrxR1/2、 Trx 1/2、Nrf2 和 HO-1 的 mRNA 表达情况。

重要结论: $\mathrm{CCl}_{4}$ 造模成功后口服檞皮素对其造成的急性肝损伤有治疗作用, 给药组小鼠血清中的转氨酶 与模型组相比均有显著下降, 通过 MDA 和免疫组化分析其机理可能和保护氧化应激损伤有 关，通过实时 PCR 分析发现 $\mathrm{CCl}_{4}$ 抑制了抗氧化酶 Prx 家族、TrxRd1、TrxRd2、Trx1、Trx2 和 Nrf2 及其下游 HO-1 的基因表达, 而檞皮素可以逆转 $\mathrm{CCl}_{4}$ 降低的这些基因的表达。

关键词组：肝毒性；氧应激损伤； Prx； Nrf2; TrxRd; Trx; HO-1 